OPEN ACCESS

Edited by:

Richard Ivell,

University of Nottingham,

United Kingdom

Reviewed by:

Gufeng Xu,

Brigham and Women's Hospital and Harvard Medical School, United States Igor Govorov,

Almazov National Medical Research

Centre, Russia

${ }^{*}$ Correspondence:

Fangxin Shi

shifangxin@sina.com

Zhen Xiao

seriousdoc@163.com

${ }^{\dagger}$ These authors have contributed equally to this work

Specialty section: This article was submitted to

Reproduction,

a section of the journal

Frontiers in Endocrinology

Received: 21 October 2020

Accepted: 12 May 2021

Published: 10 June 2021

Citation:

Zhang X, Huangfu Z, Shi F and Xiao $Z$ (2021) Predictive

Performance of Serum $\beta$-hCG

MoM Levels for Preeclampsia

Screening: A Meta-Analysis.

Front. Endocrinol. 12:619530. doi: 10.3389/fendo.2021.619530

\section{Predictive Performance of Serum $\beta$-hCG MoM Levels for Preeclampsia Screening: A Meta-Analysis}

\author{
Xiao Zhang ${ }^{1+}$, Zhao Huangfu ${ }^{2 \dagger}$, Fangxin Shi ${ }^{1 *}$ and Zhen Xiao ${ }^{1,3 *}$ \\ 1 Department of Obstetrics and Gynecology, First Affiliated Hospital of Dalian Medical University, Dalian, China, 2 Department \\ of Urology, The Second Affiliated Hospital of Dalian Medical University, Dalian, China, ${ }^{3}$ Institute of High Altitude Medicine, \\ People's Hospital of Naqu Affiliated to Dalian Medical University, Naqu, China
}

Objective: The aim of the present study was to investigate the predictive value of using the multiple of the median (MoM) of $\beta$-human chorionic gonadotropin ( $\beta$-hCG) levels in patients with preeclampsia (PE) and healthy pregnant women.

Methods: Electronic databases including PubMed, EBSCO, Ovid, Web of Science, China National Knowledge Infrastructure (CNKI), SinoMed, Wangfang and the Weipu Journal were searched up to May 31, 2020. Two reviewers independently selected the articles and extracted data on study characteristics, quality and results. A random-effects model was employed, and standardized mean difference and 95\% confidence intervals were calculated. Twenty-one case-control studies were analyzed in the present meta-analysis, including a total of 2,266 cases and 25,872 healthy controls.

Results: Women who were diagnosed with PE were found to have higher early secondtrimester levels of serum $\beta$-hCG MoM compared with healthy controls, although the levels in the first trimester were not significantly different. Ethnicity subgroup analysis demonstrated that the MoM of $\beta$-hCG serum levels was significantly higher in PE patients in both Asian and Caucasian populations during the early second trimester.

Conclusion: The MoM of $\beta$-hCG serum levels was found to be a valuable clinical indicator for predicting PE in the early second trimester, but had little predictive value in the first trimester. However, further assessment of the predictive capacity of $\beta$-hCG within larger, diverse populations is required.

Keywords: preeclampsia, $\beta$-hCG MoM levels, prediction, early second trimester, meta-analysis

\section{INTRODUCTION}

Preeclampsia (PE) is an idiopathic disease of pregnancy that may lead to multi-organ damage, and it is a multi-systemic disorder that is associated with poor early placentation and is characterized by new-onset hypertension and proteinuria after 20 weeks of gestation, with a significant impact on several organ systems, including renal and hepatic insufficiency, neurological complications, hematological complications, or evidence of uteroplacental dysfunction (1-4). PE is the second leading cause of maternal mortality on a global scale, and it is the main cause of pregnancy-related 
hospitalization. The prevalence of PE globally is $2-10 \%$, while the prevalence is higher (4-18\%) in developing countries $(5,6)$. To date, prenatal control for pregnant women and active termination of pregnancy in patients suffering from severe PE are the only effective methods for decreasing morbidity and mortality of pregnant women and their fetuses.

Although the factors affecting PE remain unclear, most studies suggest that the main pathogenic mechanism maybe inadequate trophoblast invasion into maternal spiral arteries, resulting in decreased placental blood flow, trophoblast apoptosis and proinflammatory cytokine production (7). Recent research using maternal blood and placentas from PE patients also indicates that the pathophysiological origin of PE maybe traced back to the placenta. Therefore, it would be of great value to accurately predict $\mathrm{PE}$ by identifying early proteomic biomarkers of placental dysfunction in order to apply timely interventions to reduce the prevalence of PE. To date, several biochemical markers of placental dysfunction have been used to evaluate the predictive factors of PE before the appearance of clinical symptoms. Some studies indicated that $\beta$-human chorionic gonadotropin $(\beta-h C G)$ is involved in $\mathrm{PE}$, and $\beta$-hCG has been recommended as a serum maker for screening $\mathrm{PE}$ at $8-14$ weeks of gestation $(8,9)$.

$\beta$-hCG is a glycoprotein hormone produced by trophoblast cells, which is often used to diagnose pregnancy, ectopic pregnancy and hydatidiform mole. Trophoblasts are specialized cells of the placenta that play an important role in the exchange of gases and nutrients between them other and the fetus and are involved in blastocyst attachment, placental implantation and placental vasculature (10). During normal pregnancy, the concentration of $\beta$-hCG peaks between 10 and 12 weeks, and then gradually decreases. Abnormal placental formation/function may induce changes in serum $\beta$-hCG levels (11).

Several studies have reported an association between the reduction of $\beta$-hCG MoM levels in the first trimester and the development of PE (12); however, some findings are inconsistent $(13,14)$. Some studies suggested that $\beta$-hCG MoM levels were only increased in patients with severe $\mathrm{PE}$, while there was no significant change in patients with mild PE (13). Although some scholars conducted a meta-analysis of the predictive value of serum $\beta$-hCG MoM levels indicating that $\beta$-hCG MoM levels were significantly increased in women with $\mathrm{PE}$ compared with healthy pregnant women, that study did not analyze the effect of the timing of serum $\beta$-hCG detection on its predictive value for PE (9).Subsequently, numerous studies analyzed the association between serum $\beta$-hCG MoM levels and PE, and a number of articles indicated that there was no statistically significant association between serum $\beta$-hCG MoM levels and PE (15-18). Therefore, a meta-analysis was conducted hereinto evaluate and verify the predictive value of MoM of $\beta$-hCG serum levels in PE.

\section{MATERIALS AND METHODS}

\section{Literature Search}

The electronic databases PubMed, EBSCO, Ovid, Web of Science, China National Knowledge Infrastructure (CNKI), SinoMed,
Wangfang and the Weipu Journal were searched (last search: May 31, 2020) for published studies relevant to our topic of interest, without restriction of language or data collection. Search terms were combined with $\mathrm{MeSH}$ terms ('Chorionic Gonadotropin, beta Subunit, Human' or 'Chorionic Gonadotropin') and (Pre-eclampsia') with different search terms/key words in all fields (' $\beta$-hCG' or ' $\beta$-hcg' or 'beta-hcg' or 'human chorionic gonadotropin' or 'hcg') to retrieve the relevant articles from the databases. Manual searches of cross-references were also conducted to screen for other eligible studies. The metaanalysis was registered in PROSPERO (CRD42020190736).

\section{Study Selection}

The first stage of study selection involved scrutinizing the database by 2 independent reviewers (Xiao Zhang and Zhao Huangfu) to identify articles from the title and abstract review based on keywords for $\beta$-hCG MoM and PE. In the second stage, the titles and abstracts of all the identified citations were also independently screened to identify studies that fulfilled the inclusion criteria by the same 2 reviewers to confirm study eligibility. It was discussed with senior reviewer (Fangxin Shi) if any disagreement occurred. The criteria for inclusion were as follows: i) Published studies investigating the association between $\beta$-hCG MoM and PE; ii) prospective, retrospective or nested case-control design; iii) diagnosis of $\mathrm{PE}$ confirmed by the American College of Obstetricians and Gynecologists (ACOG) [hypertension (systolic blood pressure $\geq 140 \mathrm{~mm} \mathrm{Hg}$ and/or diastolic blood pressure $\geq 90$ $\mathrm{mm} \mathrm{Hg}$, on two separate measurements conducted at least $44 \mathrm{~h}$ apart) and proteinuria ( $\geq 0.3 \mathrm{~g} /$ day urine collection and/o $\geq 1+$ on dipstick testing) after 20 weeks of gestation] and the guidelines of the International Society for the Study of Hypertension in Pregnancy (ISSHP) [systolic $\mathrm{BP} \geq 140 \mathrm{mmHg}$ or diastolic $\mathrm{BP} \geq 90$ $\mathrm{mmHg}$ on two measurements at least $4 \mathrm{~h}$ apart in previously normotensive women after 20 weeks of gestation, and proteinuria of $300 \mathrm{mg}$ or more in $24 \mathrm{~h}$ ] $(19,20)$; iv) original data provided; v) studies including singleton pregnancies only. The criteria for exclusion were abstracts, editorials, narrative reviews, case reports, letters to the editor, and meta-analyses or other types of articles that did not include primary study results. Additionally, duplicate publications or studies with overlapping data were not considered.

\section{Data Extraction and Quality Assessment}

Two independent investigators (Xiao Zhang and Zhao Huangfu) extracted a range of data from each study using a standardized data-collecting form: First author's name, year of publication, country, ethnicity, population evaluated, study design, definition and number of cases and controls, maternal age range or mean age, systolic blood pressure, diastolic blood pressure or mean arterial pressure, demographic variables, disease type, protein expression levels and P-values between cases and controls. The authors were contacted by email in cases of missing information. The methodological quality of the included trials was evaluated based on the Newcastle-Ottawa Scale (NOS) by the same 2 investigators respectively. Disagreements were resolved through discussion, or by consulting a third investigator (Fangxin Shi). 


\section{Statistical Analysis}

All the continuous data (serum $\beta$-hCG MoM levels) was presented as mean \pm standard deviation (SD). Serum concentration given as median and range were converted into mean and SD using the formula reported by Luo et al. (21), Wan et al. (22) and Shi et al. (23). The strength of the association between serum $\beta$-hCG MoM levels and PE was estimated by standardized mean differences (SMDs) and $95 \%$ confidence intervals (95\% CIs) calculated by the Z-test. Between-study heterogeneity was evaluated by the Cochran's Q statistic $\left(P<0.05\right.$ was considered significant) and $I^{2}$ tests (24). To calculate the pooled SMDs, fixed/random-effects models were used; a random-effects model was applied when there was evidence of significant heterogeneity $\left(P<0.05\right.$ or $\left.I^{2}>50 \%\right)$, and odds ratios were pooled based on the fixed-effects model $(25,26)$. If there was significant heterogeneity, subgroup analysis based on ethnicity and sample size was performed to identify potential explanatory variables for the differences in serum $\beta$-hCG MoM levels between cases and controls. Source of heterogeneity estimation was performed by univariate and multivariate meta-regression analyses, and further verification was conducted using Monte Carlo simulation (27-29). In addition, sensitivity analyses were performed to assess the effect of each single study and the stability of

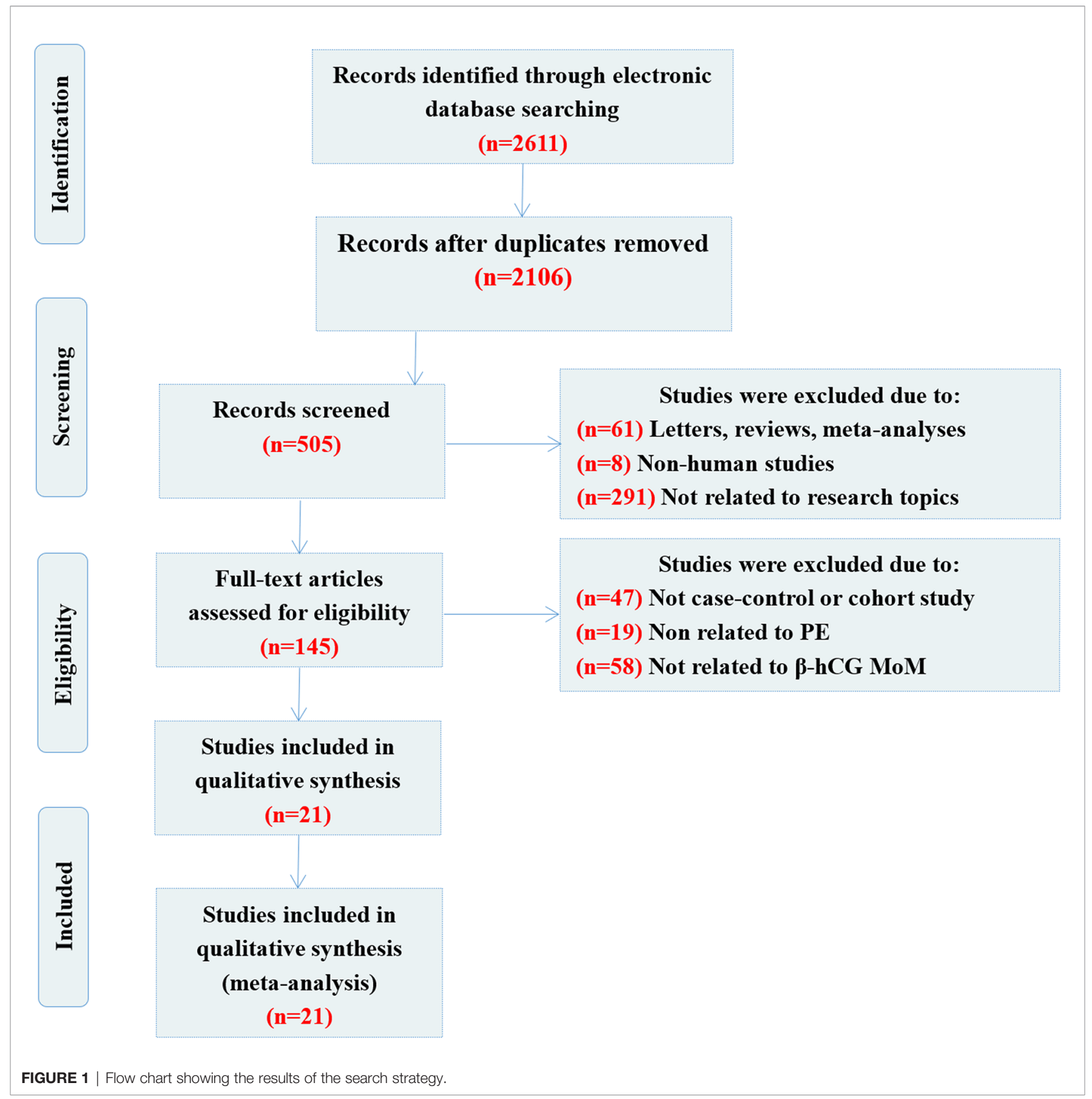


TABLE 1 | Characteristics of the included studies.

\begin{tabular}{|c|c|c|c|c|c|c|c|c|c|c|c|c|c|}
\hline \multirow[t]{2}{*}{$\begin{array}{l}\text { Reference } \\
\text { (first author) }\end{array}$} & \multirow[t]{2}{*}{ Year } & \multirow[t]{2}{*}{ Country } & \multirow[t]{2}{*}{ Ethnicity } & \multirow[t]{2}{*}{$\begin{array}{l}\text { Detection } \\
\text { method }\end{array}$} & \multicolumn{2}{|c|}{ Detection period, weeks } & \multicolumn{3}{|c|}{ Number } & \multicolumn{2}{|c|}{$\begin{array}{l}\text { Maternal age, years mean } \pm \text { standard } \\
\text { deviation or median (interquartile ranges) }\end{array}$} & \multirow[t]{2}{*}{$P$ value } & \multirow[t]{2}{*}{ NOS score } \\
\hline & & & & & case & control & size & sam-ple & case/control & case & control & & \\
\hline Long W & 2018 & China & Asian & TRFIA & $15-20$ & $15-20$ & large & 1369 & 198/1171 & $27.7 \pm 3.6$ & $26.6 \pm 3.5$ & 0.09 & 6 \\
\hline Papastefanou I & 2018 & Germany & Caucasians & ELISA & $11-14$ & $11-14$ & small & 277 & $12 / 265$ & $31.9 \pm 3.7$ & $31 \pm 4.2$ & 0.958 & 7 \\
\hline YuN & 2017 & China & Asian & TRFIA & $11-13^{+6}$ & $11-13^{+6}$ & large & 662 & $462 / 200$ & $30.2 \pm 4.6$ & $28.6 \pm 2.3$ & 0.536 & 7 \\
\hline Kim SY & 2016 & Korea & Asian & TRFIA & $15-20$ & $15-20$ & small & 118 & $34 / 84$ & $34.1(32.7-36.0)$ & 33.0(31.0-35.3) & $>0.05$ & 6 \\
\hline Zheng QZ & 2016 & China & Asian & ELISA & $15-20$ & $15-20$ & small & 259 & 63/196 & $31.8 \pm 4.3$ & $31.5 \pm 7.5$ & 0.013 & 6 \\
\hline Crovetto F & 2015 & Spain & Caucasians & DELFIA & $10.6 \pm 3.9$ & $10.6 \pm 3.9$ & small & 340 & $40 / 300$ & $33.9 \pm 6.4$ & $32.7 \pm 4.7$ & $<0.05$ & 7 \\
\hline Crovetto F & 2014 & Spain & Caucasians & DELFIA & 10.1(9.1-10.6) & $10.2(9-10.6)$ & large & 9462 & 303/9159 & $32.3 \pm 6.1$ & $31.7 \pm 5.3$ & $<0.001$ & 8 \\
\hline Karahasanovic A & 2014 & Denmark & Caucasians & ELISA & $11.1(8-14)$ & $11(8-11)$ & small & 249 & $161 / 88$ & $30.9(18.8-41.2)$ & $28.1(21.1-40.7)$ & $<0.05$ & 7 \\
\hline Ozdamar O & 2014 & Turkey & Caucasians & UA & $12.4 \pm 0.6$ & $12.4 \pm 0.7$ & small & 240 & $60 / 180$ & $29.3 \pm 5.7$ & $28.1 \pm 4.3$ & 0.882 & 6 \\
\hline Teixeira C & 2014 & Portugal & Caucasians & DELFIA & $9-13^{+6}$ & $9-13^{+6}$ & large & 4799 & $140 / 4659$ & $31.0(27.7-33.6)$ & 29.9(25.8-33.0) & $>0.05$ & 6 \\
\hline Lai J & 2013 & UK & Caucasians & DELFIA & $11-13^{+6}$ & $11-13^{+6}$ & small & 300 & $50 / 250$ & $29.8(24.2-33.8)$ & $31.2(27.6-34.9)$ & $>0.05$ & 7 \\
\hline Suri S & 2013 & UK & Caucasians & DELFIA & $11-14$ & $11-14$ & small & 56 & $14 / 42$ & NR & NR & NS & 7 \\
\hline Kuc S & 2013 & Netherlands & Caucasians & DELFIA & $12.0 \pm 1.2$ & $12.5 \pm 0.7$ & large & 667 & $167 / 500$ & $33.2 \pm 4.8$ & $32.6 \pm 3.7$ & NS & 6 \\
\hline Wortelboer EJ & 2010 & Netherlands & Caucasians & DELFIA & $8-13^{+6}$ & $8-13^{+6}$ & large & 568 & $88 / 480$ & $34.6(31.0-37.3)$ & $36.0(33.3-38.2)$ & 0.93 & 7 \\
\hline Staboulidou I & 2009 & UK & Caucasians & NR & $11-13$ & $11-13$ & large & 2029 & $165 / 1864$ & $31.9 \pm 7.0$ & $32.0 \pm 5.9$ & NS & 6 \\
\hline Spencer K & 2006 & UK & Caucasians & ELISA & $11-13^{+6}$ & $11-13^{+6}$ & small & 168 & $24 / 144$ & NR & NR & 0.003 & 7 \\
\hline Spencer K & 2005 & UK & Caucasians & ELISA & $11-13^{+6}$ & $11-13^{+6}$ & large & 4063 & 64/3999 & $29(17-44)$ & $30(16-47)$ & 0.266 & 6 \\
\hline Tsai MS & 2002 & Taiwan & Asian & ELISA & $10-13$ & $10-13$ & large & 711 & $46 / 665$ & $30(20-43)$ & NR & NS & 6 \\
\hline Lee LC & 2000 & Taiwan & Asian & MEIA & $15-20$ & $15-20$ & large & 1052 & 95/957 & $30.0 \pm 4.7$ & $28.6 \pm 4.1$ & $<0.001$ & 6 \\
\hline Raty R & 1999 & Finland & Caucasians & TRFIA & $16.4 \pm 1.5$ & $15.9 \pm 1.2$ & small & 343 & 10/282 & $26.2 \pm 3.0$ & $29.7 \pm 3.5$ & $>0.05$ & 7 \\
\hline Luckas M & 1998 & UK & Caucasians & RIA & 15-18 & $15-18$ & small & 406 & $19 / 387$ & $22 \pm 5.4$ & $25.1 \pm 5.6$ & 0.03 & 6 \\
\hline
\end{tabular}

DELFIA, Dissociation-enhanced lanthanide fluoroimmunoassay; UA, ultrasonographic assessment; ELISA, enzyme-linked immunosorbent assay; MEIA, microparticle enzyme immunoassay; TRFIA, time-resolved fluorescence immunoassay; RIA, radioimmunoassay; TSI, two-site immunometric assay; CLIA, chemiluminescence immunoassay; NR, not reported; NS, no significance. 
the meta-analysis results by sequential removal of individual studies. Furthermore, the effect of publication bias was detected by funnel plot, Galbraith plot and Egger's linear regression test $(P<0.05$ was considered significant) $(30,31)$. Statistical analyses were conducted with Stata statistical software, version 15.1 (Stata Corporation, College Station, Texas, USA).

\section{RESULTS}

\section{Selection of Eligible Studies}

A flow chart showing the detailed study inclusion and exclusion process is presented in Figure 1. The primary search yielded 2,611 articles (including a manual search, $n=2$ ), 2,106 of which were repetitive publications and were excluded. A total of 360 articles were removed as they were reviews or meta-analyses $(n=61)$, nonhuman studies $(n=8)$ or unrelated to the topic $(n=291)$. After further evaluation, 124 studies were removed following a more detailed full-text assessment, including 47 studies that were not cohort or case-control studies, 19 studies that were unrelated to PE and 58 that were unrelated to $\beta$-hCG MoM. Finally, 21 casecontrol publications were selected for inclusion in this metaanalysis (12-18, 32-45). The enrolled studies were of moderate to high quality, and the NOS assessments for each included study are summarized in Table 1.

\section{Baseline Information of the Included Studies}

The 21 selected studies included a total of 28,138 subjects, with 2,266 cases and 25,872 healthy controls. The sample size ranged between 56 and 9,462. Of these studies, 15 were in Caucasian populations and 6 studies were performed in Asian populations. $\beta$ hCG was detected in the early second trimester in 6 studies and in the first trimester in the remaining studies; 10 studies were largesample studies and the remaining 11 were small-sample studies. A total of 6 different methods were used to measure serum $\beta$-hCG levels in the included studies: Dissociation-enhanced lanthanide fluoroimmunoassay was used in 7 studies, time-resolved fluorescence immunoassay was used in 4 studies, enzyme-linked immunosorbent assay was used in 6 studies, and the remaining methods (ultrasonographic assessment, microparticle enzyme immunoassay and radioimmunoassay, two-site immunometric assay, chemiluminescence immunoassay) were utilized in 4 separate studies. A total of 7 studies had statistically significant differences between the case and control groups, while the remaining 14 studies exhibited no statistically significant differences (Table 1).

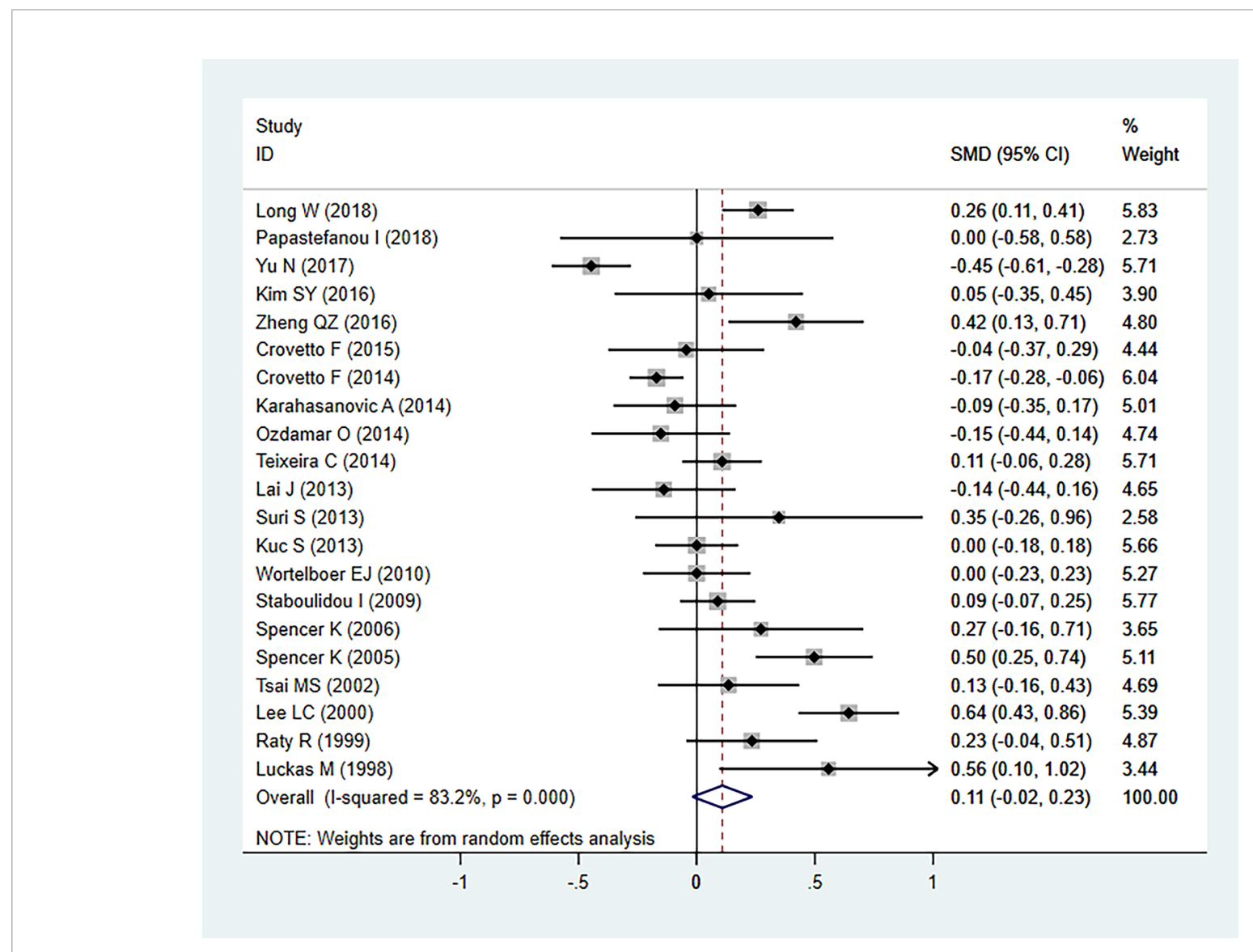

FIGURE 2 | Random-effect model forest plot for the association between serum $\beta$-hCG MoM levels and PE. 


\section{$\beta$-hCG MoM Expression Levels and PE}

In our meta-analysis, we detected significant heterogeneity $\left(I^{2}=\right.$ 83.2\%, $P=000$ ), and therefore the random-effects model was applied. Statistical analysis revealed no significant differences in serum $\beta$-hCG MoM levels between patients with PE and controls $(\mathrm{SMD}=0.108,95 \% \mathrm{CI}=-0.019-0.235, \mathrm{z}=1.67, P=0.094$ ) (Figure 2). As heterogeneity was observed, the association between the serum $\beta$-hCG MoM levels and PE was evaluated for subgroups by sample size, detection period, ethnicity, and diagnostic criteria for PE. Our results demonstrated that, apart from the detection period subgroup, all other subgroups exhibited no significant differences.

In the sample size-stratified subgroup analysis, serum $\beta$-hCG MoM levels were not significantly different between PE patients in the small size subgroup $(\mathrm{SMD}=0.106,95 \% \mathrm{CI}=-0.042-0.253$, $\mathrm{Z}=1.40, P=0.161)$ and the large size subgroup ( $\mathrm{SMD}=0.104,95 \%$ $\mathrm{CI}=-0.082-0.291, \mathrm{z}=1.10, P=0.273$ ) (Figure 3A).

In the ethnicity-stratified subgroup analysis, serum $\beta$-hCG MoM levels were not significantly different between PE patients in the Caucasian subgroup $(\mathrm{SMD}=0.067,95 \% \mathrm{CI}=-0.043-0.177$,
$\mathrm{Z}=1.20, P=0.230)$ and the Asian subgroup ( $\mathrm{SMD}=0.176,95 \%$ $\mathrm{CI}=-0.180-0.532, \mathrm{z}=0.97, P=0.332$ ) (Figure 3B).

In the diagnostic criteria for PE-stratified subgroup analysis, there was no significant difference in serum $\beta$-hCG MoM levels between PE patients in the ACOG standard subgroup $(\mathrm{SMD}=0.126,95 \% \mathrm{CI}=-0.164-0.417, \mathrm{z}=0.85, P=0.395)$ and the ISSHP standard subgroup $(\mathrm{SMD}=0.086,95 \% \mathrm{CI}=-0.034-0.206$, $\mathrm{Z}=1.40, P=0.161$ ) (Figure 3C).

In the detection period-stratified subgroup analysis, serum $\beta$ hCG MoM levels were higher in PE patients in the second-trimester subgroup ( $\mathrm{SMD}=0.365,95 \% \mathrm{CI}=0.192-0.539, \mathrm{z}=4.12, P=0.000)$ compared with those in the first-trimester subgroup ( $\mathrm{SMD}=0.002$, 95\% $\mathrm{CI}=-0.121-0.126, \mathrm{z}=0.03, P=0.973$ ) (Figure 3D).

Furthermore, the MoM of serum $\beta$-hCG levels in second trimester was significantly higher in $\mathrm{PE}$ patients in both the large $(\mathrm{SMD}=0.444,95 \% \mathrm{CI}=0.067-0.820, \mathrm{z}=2.31, P=0.021)$ and small $(\mathrm{SMD}=0.307,95 \% \mathrm{CI}=0.122-0.491, \mathrm{z}=3.25, P=0.001)$ sample size subgroups (Figure 4A), in both the Asian ( $\mathrm{SMD}=0.367,95 \%$ $\mathrm{CI}=0.135-0.599, \mathrm{z}=3.10, P=0.002)$ and Caucasian $(\mathrm{SMD}=0.341$,
A

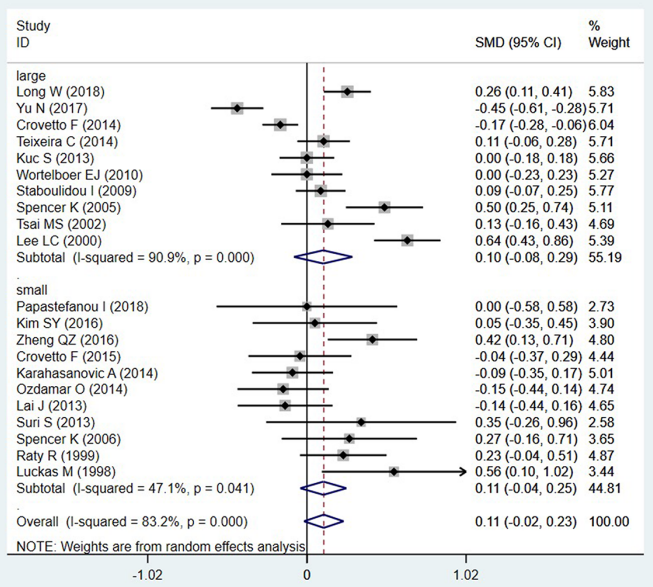

C

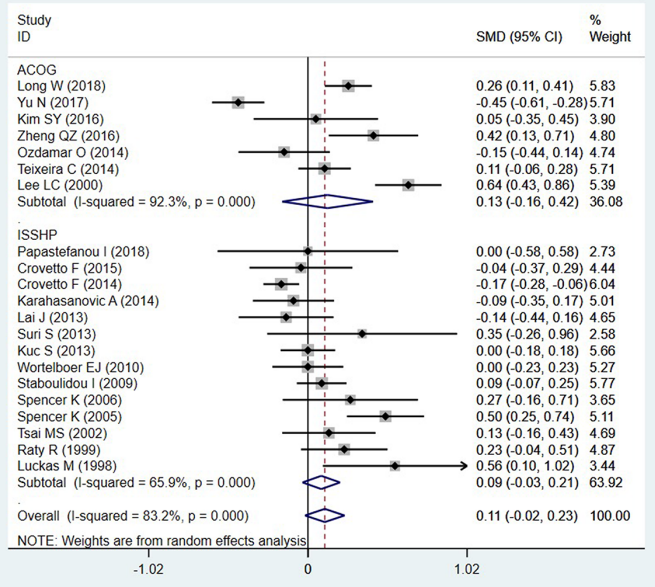

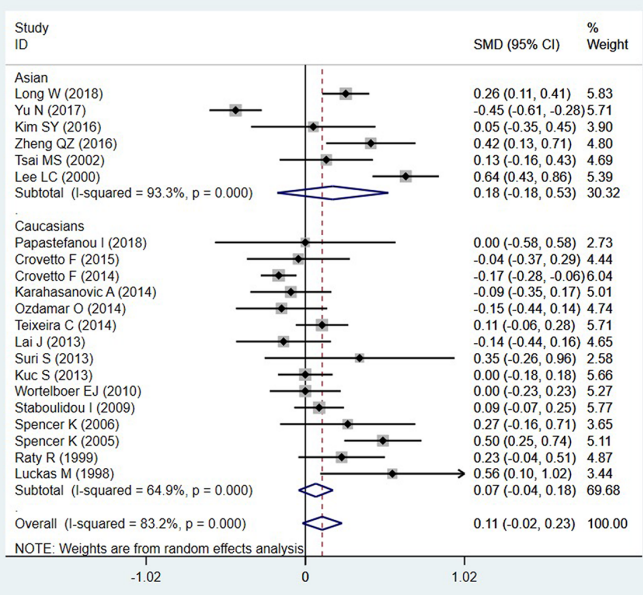

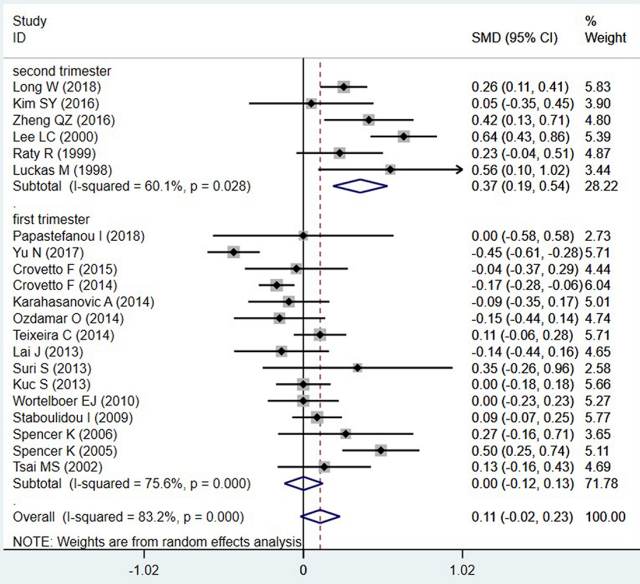

D

B

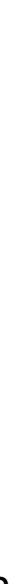

D 


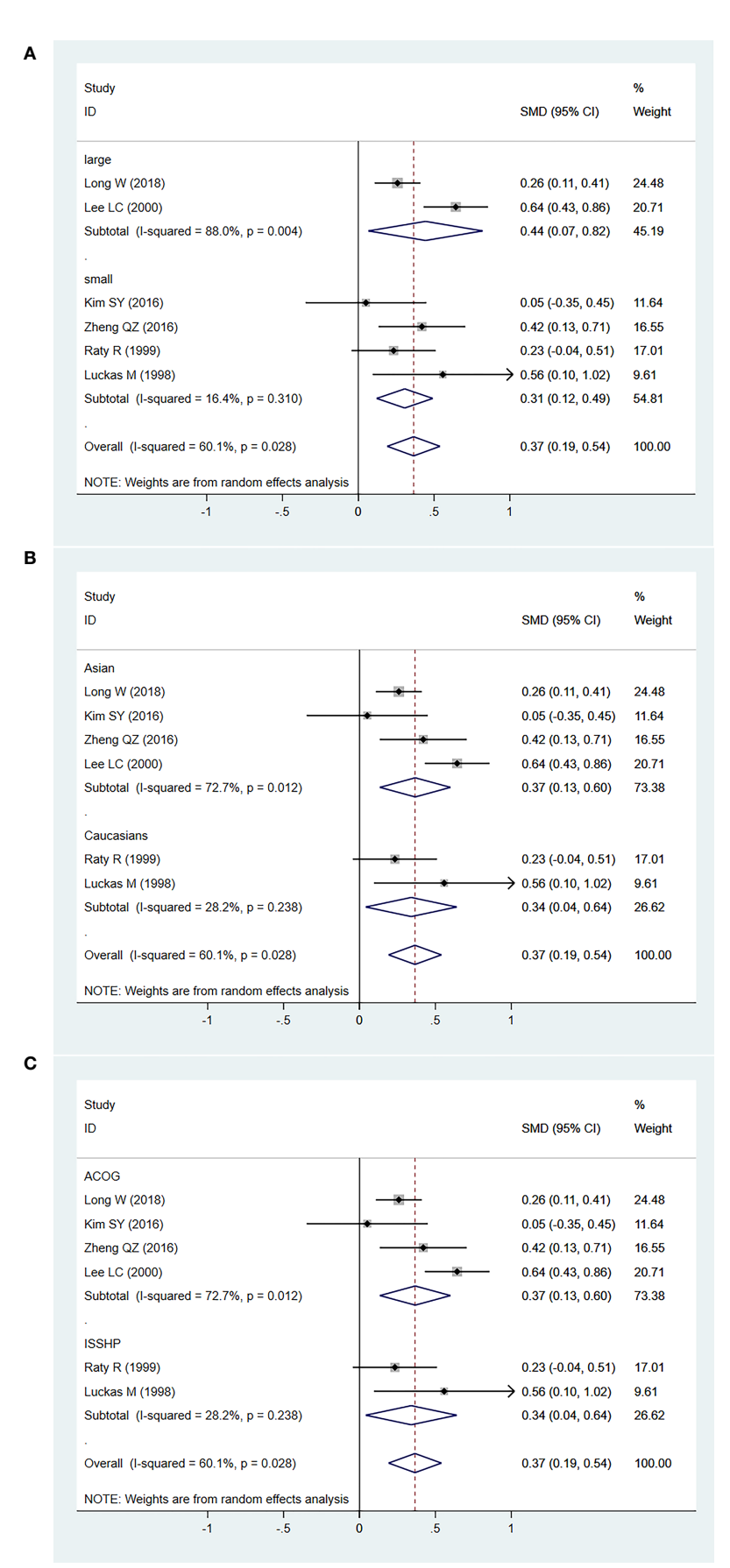

FIGURE 4 | Random-effect forest plot for the subgroup analysis for the association between serum $\beta$-hCG MoM levels in the early second trimester and PE according to (A) sample size, (B) ethnicity, (C) diagnostic criteria for PE.

95\% CI $=0.041-0.640, \quad \mathrm{Z}=2.232, \quad P=0.026)$ populations (Figure 4B), and in both the ACOG diagnostic criteria for PE (SMD $=0.367,95 \% \mathrm{CI}=0.135-0.599, \mathrm{z}=3.10, P=0.002)$ and ISSHP diagnostic criteria for $\mathrm{PE}(\mathrm{SMD}=0.341,95 \% \mathrm{CI}=0.041-0.640$, $\mathrm{Z}=2.232, P=0.026$ ) subgroups (Figure 4C).
Based on univariate and multivariate meta-regression analyses, ethnicity, country, diagnostic criteria for PE, detection method and sample size were neither the sources of heterogeneity nor the key factors of overall effect size (all $P>0.05$ ) (Figure 5 and Table 2). However, year of publication $(P=0.006)$ and detection period $(P=0.005)$ may be considered as sources of heterogeneity.

\section{Sensitivity Analysis and Publication Bias}

We conducted a sensitivity analysis of the present meta-analysis, and the results demonstrated that no single study had an impact on the overall estimate of the association between serum $\beta$-hCG MoM levels and PE progression (Figure 6A). In addition, Begg's funnel plot (Figure 6B) and Galbraith plot (Figure 6C) did not reveal any obvious asymmetry, and Egger's regression test suggested the absence of publication bias $(P=0.173)$.

\section{DISCUSSION}

$\beta$-hCG is a glycoprotein hormone synthesized by placental trophoblast cells, and hCG stimulates trophoblast proliferation and invasion, thereby promoting placental growth (46). The abnormal increase in hCG levels is considered to be the result of decreased placental perfusion related to low oxidation stemming. The histological studies conducted by Lieppman et al. demonstrated that cytotrophoblasts' abnormal placentation was induced by hypoxia (47). Some studies have reported an association between $\beta$-hCG and PE, but their results were different; for example, the serum $\beta$-hCG concentrations or $\beta$ hCG MoM levels were significantly higher in pregnancies that subsequently developed PE (48). A higher $\beta$-hCG MoM $(\geq 2.31)$ was associated with a higher risk of PE (15). High levels of $\beta$ hCG MoM ( $\geq 95 \%$ percentile) were associated with severe PE (RR 2.5-11.7) (49). Using a cutoff concentration of $2.0 \mathrm{MoM}$ of $\beta$ hCG in both the primigravida and multigravida groups, the area below the curve, sensitivity, specificity, positive predictive value, negative predictive value and positive likelihood ratio were 0.96 and $0.95,88.5$ and $100 \%, 92.0$ and $85.6 \%, 0.46$ and $0.25,0.99$ and 1.0 , and 11.1 and 6.9 for the two groups, respectively (50). Other studies suggested that the serum $\beta$-hCG level is increased in pregnancies with established PE and in the third trimester before clinical onset of the disease, but is reduced or unaltered at 11-13 weeks of gestation $(12,35,51-54)$. In 2015, a meta-analysis demonstrated that the serum $\beta$-hCG MoM levels were significantly increased in PE patients compared with those in the control group, and screening for serum $\beta$-hCG MoM levels may be useful for the early identification of pregnancies who are at risk of developing PE (9). However, most recent studies suggested that the serum $\beta$-hCG MoM levels were not significantly different between patients with $\mathrm{PE}$ and normal pregnancies (15-18). Therefore, the predicted value of serum $\beta$-hCG MoM levels for PE must be re-evaluated.

The MoM of $\beta$-hCG is a concentration index representing the MoM of normal $\beta$-hCG levels found in healthy pregnant women (55). We used a meta-analysis-based approach to perform an 
A

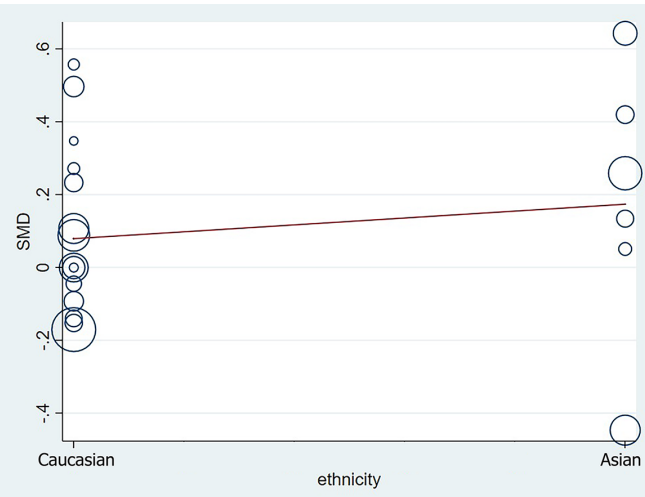

c

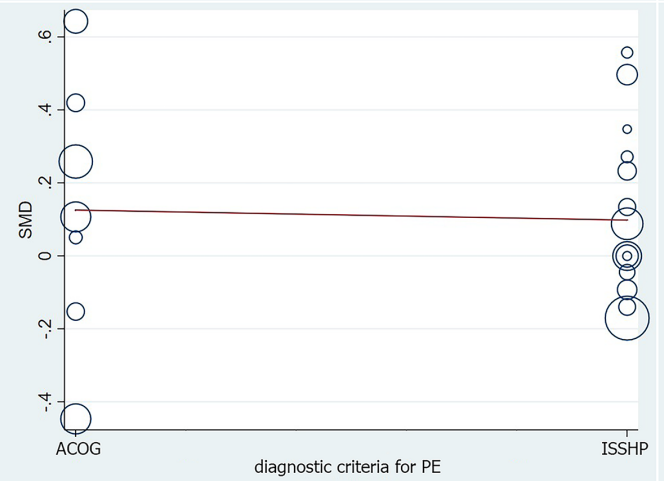

E

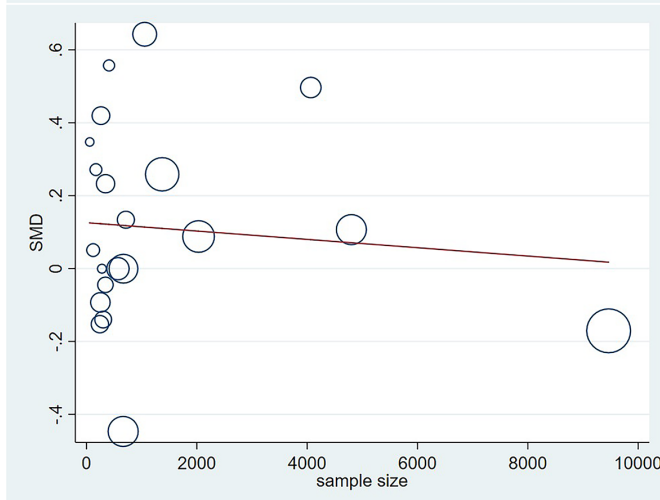

G

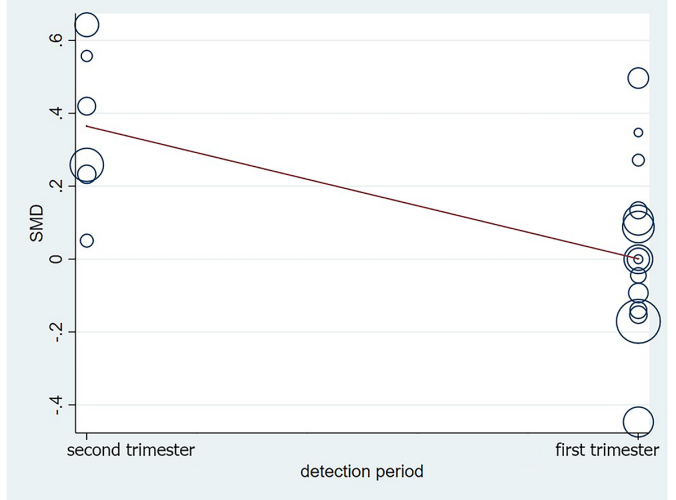

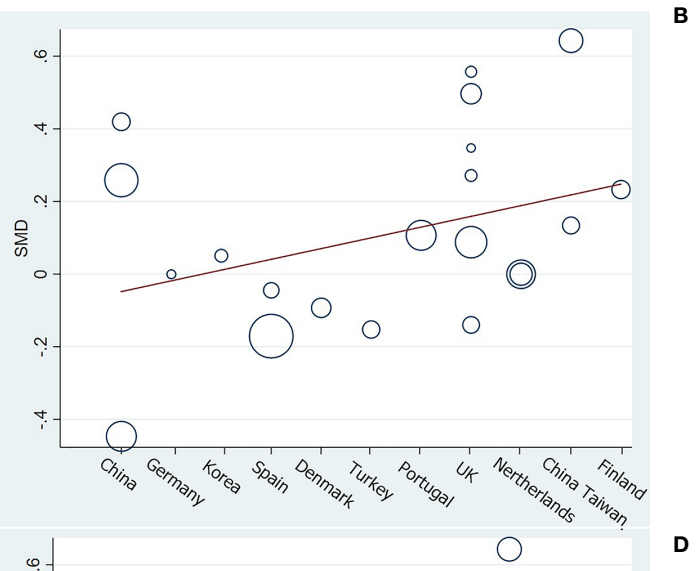
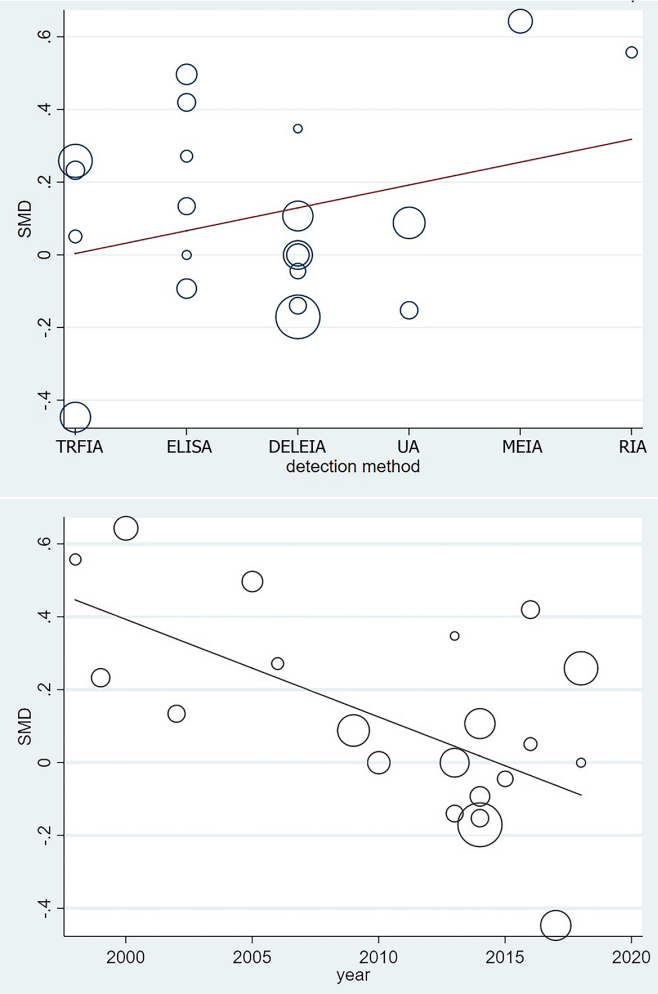

FIGURE 5 | Meta-regression analysis on (A) ethnicity, (B) country, (C) diagnostic criteria for PE, (D) detection method, (E) sample size, (F) year of publication and (G) detection period on the basis of the 21 included case-control. 
TABLE 2 | Meta-regression analysis of potential source of heterogeneity.

\begin{tabular}{|c|c|c|c|c|c|c|}
\hline \multirow{2}{*}{$\begin{array}{l}\text { Heterogeneity } \\
\text { factors }\end{array}$} & \multirow[t]{2}{*}{ Coefficient } & \multirow[t]{2}{*}{ SE } & \multirow[t]{2}{*}{$\mathbf{t}$} & \multirow{2}{*}{$\begin{array}{c}P \text { value } \\
\text { (adjusted) }\end{array}$} & \multicolumn{2}{|c|}{$95 \% \mathrm{Cl}$} \\
\hline & & & & & LL & UL \\
\hline $\begin{array}{l}\text { Year of } \\
\text { publication }\end{array}$ & -0.027 & 0.009 & -3.09 & 0.006 & -0.045 & -0.009 \\
\hline Ethnicity & 0.095 & 0.137 & 0.69 & 0.499 & -0.193 & 0.382 \\
\hline Country & 0.030 & 0.019 & 1.57 & 0.133 & -0.010 & 0.069 \\
\hline $\begin{array}{l}\text { Diagnostic criteria } \\
\text { for PE }\end{array}$ & -0.027 & 0.133 & -0.21 & 0.839 & -0.310 & 0.251 \\
\hline Detection method & 0.063 & 0.049 & 1.28 & 0.216 & -0.040 & 0.166 \\
\hline Detection period & -0.364 & 0.115 & -3.16 & 0.005 & -0.605 & -0.123 \\
\hline Sample size & -0.000 & 0.000 & -0.43 & 0.674 & -0.000 & 0.000 \\
\hline
\end{tabular}

assessment of the predictive value of $\beta$-hCG MoM in the early detection of PE. The results demonstrated that the serum $\beta$-hCG MoM levels of PE patients were not significantly different compared to those of healthy women in the first trimester, but may have a certain clinical value for predicting PE in the early second trimester, which is consistent with the results of previous studies $(13,14,36,50,56)$. Gestational week may affect the correlation between $\beta$-hCG MoM and PE. Serum $\beta$-hCG MoM levels improve the prediction of $\mathrm{PE}$ in the early second trimester, but the improvement is small, and it may not be a useful marker of $\mathrm{PE}$ in the first trimester. Therefore, it may be necessary to combine other indicators to improve the sensitivity and specificity of predicting PE. In order to identify the influence of other factors, such as ethnicity, sample size and diagnostic criteria for PE, on the predictive value of $\beta$-hCG MoM in PE patients, a subgroup analysis was performed. Regardless of ethnicity-stratified analysis or sample size-stratified analysis or diagnostic criteria for PE-stratified analysis, we found that $\beta$ hCG was of no value for the prediction of PE in 18 included studies. However, for the 6 studies in which detection was only performed in the second trimester, the levels of serum $\beta$-hCG MoM were significantly higher in patients with $\mathrm{PE}$ in both Asian and Caucasian populations.

Although this was a meta-analysis on the association between $\beta$-hCG MoM and PE, the whole sample size was small and no subgroup analysis was performed for detection period. A number of scholars have repeatedly investigated the value of $\beta$-hCG for $\mathrm{PE}$ in recent years, but their results differ, and the majority indicate that there is no association between $\beta$-hCG MoM and $\mathrm{PE}$; thus, it was deemed necessary to perform another metaanalysis. We hypothesized that the reason for these results maybe that the pathological changes of PE in the first trimester are mainly caused by defective trophoblast invasion, leading to reduced uteroplacental blood flow at approximately 12 weeks of gestation, with little or no influence of $\beta$-hCG levels, whereas subsequent oxidative stress and other reactions occurring in the placenta in the early second trimester induce higher $\beta$-hCG levels (57).

There were certain limitations to the present study. First, the heterogeneity between studies was high. To overcome this, various subgroup analyses were performed to explore the different causes of heterogeneity, thus yielding better accuracy values in the subgroup analyses. We did not perform meta-

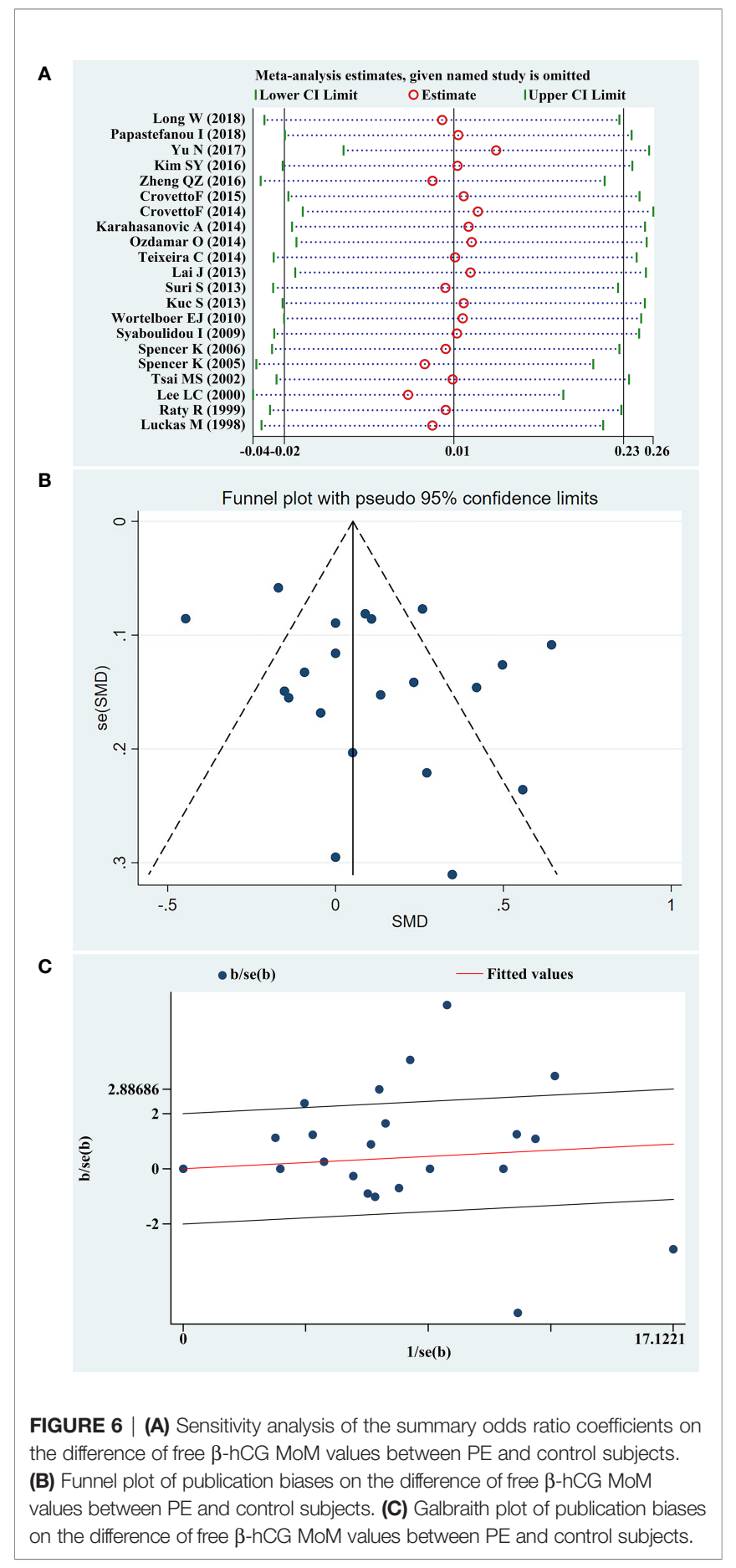

regression on the early second trimester subgroup to find its heterogeneity source due to the number of included studies being $<10$. Second, the treatment was not randomized in the study, which means the predictive value for $\beta$-hCG MoM levels from this sample set could not be identified. Third, the methods used for measuring $\beta$-hCG MoM levels were not the same, and the 6 different methods may cause selection bias. Fourth, three of the included articles were not high-quality articles, which may 
have affected the final results. Fifth, considering the relatively high morbidity and mortality rates associated with $\mathrm{PE}$, it would be best to identify as many patients as possible; higher-risk populations maybe excluded due to the narrower false-positive rate, and the lack of detection of false-positive and false-negative rates may have limited the reliability of our results. Finally, the detection period of $\beta$-hCG was only divided into two stages instead of some definitive gestational weeks. Perhaps a more narrowed detection period could further enhance the predictive value of serum $\beta$-hCG MoM level.

\section{CONCLUSION}

In conclusion, it was demonstrated that serum $\beta$-hCG MoM levels were higher in PE patients in the early second trimester compared with those in healthy pregnant women, which may represent a possible screening method for early prediction and potential interventions in PE. Further investigations are required, including a prospective assessment of patients with $\mathrm{PE}$ and evaluation of the optimal cut-off value for $\beta$-hCG MoM, in order to develop an applicable predictive tool for routine pregnancy monitoring and management, maximize the predictive potential sensitivity and specificity, and elucidate the potential underlying mechanism.

\section{REFERENCES}

1. Lim R, Barker G, Lappas M. TREM-1 Expression Is Increased in Human Placentas From Severe Early-Onset Preeclamptic Pregnancies Where it may Be Involved in Syncytialization. Reprod Sci (Thousand Oaks Calif.) (2014) 21:562-72. doi: 10.1177/1933719113503406

2. Nikolic A, Cabarkapa V, Novakov Mikic A, Jakovljević A, Stosic Z. Ceruloplasmin and Antioxidative Enzymes in Pre-Eclampsia. J MaternalFetal Neonatal Med (2016) 29:2987-93. doi: 10.3109/14767058.2015.1111333

3. Novakov Mikic A, Cabarkapa V, Nikolic A, Maric D, Brkic S, Mitic G, et al. Cystatin C in Pre-Eclampsia. J Maternal-Fetal Neonatal Med (2012) 25:961-5. doi: 10.3109/14767058.2011.601366

4. Tranquilli AL, Dekker G, Magee L, Roberts J, Sibai BM, Steyn W, et al. The Classification, Diagnosis and Management of the Hypertensive Disorders of Pregnancy: A Revised Statement From the ISSHP. Pregnancy Hypertension (2014) 4:97-104. doi: 10.1016/j.preghy.2014.02.001

5. Al-Jameil N, Tabassum H, Ali MN, Qadeer MA, Khan FA, Al-Rashed M. Correlation Between Serum Trace Elements and Risk of Preeclampsia: A Case Controlled Study in Riyadh, Saudi Arabia. Saudi J Biol Sci (2017) 24:1142-8. doi: 10.1016/j.sjbs.2015.02.009

6. Ugwuja EI, Famurewa AC, Ikaraoha CI. Comparison of Serum Calcium and Magnesium Between Preeclamptic and Normotensive Pregnant Nigerian Women in Abakaliki, Nigeria. Ann Med Health Sci Res (2016) 6:33-7. doi: 10.4103/2141-9248.180269

7. Rolfo A, Giuffrida D, Nuzzo AM, Pierobon D, Cardaropoli S, Piccoli E, et al. Pro-Inflammatory Profile of Preeclamptic Placental Mesenchymal Stromal Cells: New Insights Into the Etiopathogenesis of Preeclampsia. PloS One (2013) 8:e59403. doi: 10.1371/journal.pone.0059403

8. Wortelboer EJ, Koster MP, Kuc S, Eijkemans MJ, Bilardo CM, Schielen PC, et al. Longitudinal Trends in Fetoplacental Biochemical Markers, Uterine Artery Pulsatility Index and Maternal Blood Pressure During the First Trimester of Pregnancy. Ultrasound Obstetrics Gynecol (2011) 38:383-8. doi: 10.1002/uog.9029

9. Liu HQ, Wang YH, Wang LL, Hao M. Predictive Value of Free $\beta$-Hcg Multiple of the Median for Women With Preeclampsia. Gynecologic Obstetric Invest (2015) 81:137-47. doi: 10.1159/000433434

\section{DATA AVAILABILITY STATEMENT}

The original contributions presented in the study are included in the article. Further inquiries can be directed to the corresponding authors.

\section{AUTHOR CONTRIBUTIONS}

$\mathrm{XZ}$ and $\mathrm{ZH}$ have worked on the whole article, who contributed equally to this article. FS and ZX were corresponding authors who have guided the research. All authors agree to be accountable for the content of the work. All authors contributed to the article and approved the submitted version.

\section{FUNDING}

This study was supported by Tibet Local Science and Technology Project guided by Central Government (Grant No. XZ202001YD0005C), Scientifical Funds of Medical Assistance Program for Tibet from Tibet Health Committee(Grant No. XZ2020ZR-ZY78(Z)), the Natural Science Funds of Liaoning (Grant No.: 2019-BS-073).

10. Ding X, Yang KL. Antibody-Free Detection of Human Chorionic Gonadotropin by Use of Liquid Crystals. Analytical Chem (2013) 85:10710-6. doi: 10.1021/ac400732n

11. El-Baradie SM, Mahmoud M, Makhlouf HH. Elevated Serum Levels of interleukin-15, interleukin-16, and Human Chorionic Gonadotropin in Women With Preeclampsia. J Obstetrics Gynaecol Can (2009) 31:142-8. doi: 10.1016/s1701-2163(16)34098-1

12. Karahasanovic A, Sørensen S, Nilas L. First Trimester Pregnancy-Associated Plasma Protein A and Human Chorionic Gonadotropin-Beta in Early and Late Pre-Eclampsia. Clin Chem Lab Med (2014) 52:521-5. doi: 10.1515/cclm2013-0338

13. Zheng Q, Deng Y, Zhong S, Shi Y. Human Chorionic Gonadotropin, Fetal Sex and Risk of Hypertensive Disorders of Pregnancy: A Nested Case-Control Study. Pregnancy Hypertension (2016) 6:17-21. doi: 10.1016/j.preghy. 2016.01.006

14. Lee LC, Sheu BC, Shau WY, Liu DM, Lai TJ, Lee YH, et al. Mid-Trimester beta-hCG Levels Incorporated in a Multifactorial Model for the Prediction of Severe Pre-Eclampsia. Prenatal Diagnosis (2000) 20:738-43. doi: 10.1002/ 1097-0223(200009)20:9<738::aid-pd917>3.0.co;2-r

15. Long W, Zhou Q, Wang H, Lu B, Chen Y, Zhang B, et al. Second-Trimester Maternal Serum Screening Biomarkers in the Risk Assessment for Preeclampsia. Ann Clin Lab Sci (2018) 48:308-13.

16. Papastefanou I, Chrelias C, Siristatidis C, Kappou D, Eleftheriades M, Kassanos D. Placental Volume at 11 to 14 Gestational Weeks in Pregnancies Complicated With Fetal Growth Restriction and Preeclampsia. Prenatal Diagnosis (2018) 38:928-35. doi: 10.1002/pd.5356

17. Yu N, Cui H, Chen X, Chang Y. First Trimester Maternal Serum Analytes and Second Trimester Uterine Artery Doppler in the Prediction of Preeclampsia and Fetal Growth Restriction. Taiwanese J Obstetrics Gynecol (2017) 56:35861. doi: 10.1016/j.tjog.2017.01.009

18. Kim SY, Kim HJ, Park SY, Han YJ, Choi JS, Ryu HM. Early Prediction of Hypertensive Disorders of Pregnancy Using Cell-Free Fetal DNA, Cell-Free Total DNA, and Biochemical Markers. Fetal Diagnosis Ther (2016) 40:255-62. doi: 10.1159/000444524

19. Brown MA, Lindheimer MD, de Swiet M, Van Assche A, Moutquin JM. The Classification and Diagnosis of the Hypertensive Disorders of Pregnancy: 
Statement From the International Society for the Study of Hypertension in Pregnancy (ISSHP). Hypertension Pregnancy (2001) 20:IX-XIV. doi: 10.1081/ prg-100104165

20. Practice ACOG Committee on Obstetric. ACOG Practice Bulletin. Diagnosis and Management of Preeclampsia and Eclampsia. Number 33, January 2002. American College of Obstetricians and Gynecologists. Int J Gynaecol Obstetrics (2002) 77:67-75. doi: 10.1016/s0020-7292(02)80002-9

21. Luo D, Wan X, Liu J, Tong T. Optimally Estimating the Sample Mean From the Sample Size, Median, Mid-Range, and/or Mid-Quartile Range. Stat Methods Med Res (2018) 27:1785-805. doi: 10.1177/096228021 6669183

22. Wan X, Wang W, Liu J, Tong T. Estimating the Sample Mean and Standard Deviation From the Sample Size, Median, Range and/or Interquartile Range. BMC Med Res Method (2014) 14:135. doi: 10.1186/1471-2288-14-135

23. Shi J, Luo D, Weng H, Zeng XT, Lin L, Chu H, et al. Optimally Estimating the Sample Standard Deviation From the Five-Number Summary. Res Synthesis Methods (2020) 11:641-54. doi: 10.1002/jrsm.1429

24. Zintzaras E, Ioannidis JP. HEGESMA: Genome Search Meta-Analysis and Heterogeneity Testing. Bioinf (Oxford England) (2005) 21:3672-3. doi: 10.1093/bioinformatics/bti536

25. Higgins JP, Thompson SG. Quantifying Heterogeneity in a Meta-Analysis. Stat Med (2002) 21:1539-58. doi: 10.1002/sim.1186

26. Zintzaras E, Ioannidis JP. Heterogeneity Testing in Meta-Analysis of Genome Searches. Genet Epidemiol (2005) 28:123-37. doi: 10.1002/gepi.20048

27. Ferrenberg AM, Swendsen RH. New Monte Carlo Technique for Studying Phase Transitions. Phys Rev Lett (1988) 61:2635-8. doi: 10.1103/ PhysRevLett.61.2635

28. Huizenga HM, Visser I, Dolan CV. Testing Overall and Moderator Effects in Random Effects Meta-Regression. Br J Math Stat Psychol (2011) 64:1-19. doi: $10.1348 / 000711010 \times 522687$

29. Jackson D, White IR, Riley RD. Quantifying the Impact of Between-Study Heterogeneity in Multivariate Meta-Analyses. Stat Med (2012) 31:3805-20. doi: $10.1002 / \operatorname{sim} .5453$

30. Peters JL, Sutton AJ, Jones DR, Abrams KR, Rushton L. Comparison of Two Methods to Detect Publication Bias in Meta-Analysis. JAMA (2006) 295:67680. doi: $10.1001 /$ jama.295.6.676

31. Song F, Gilbody S. Bias in Meta-Analysis Detected by a Simple, Graphical Test. Increase in Studies of Publication Bias Coincided With Increasing Use of Meta-Analysis. BMJ (Clinical Res ed.) (1998) 316:471. doi: 10.1136/ bmj.315.7109.629

32. Crovetto F, Figueras F, Triunfo S, Crispi F, Rodriguez-Sureda V, Dominguez C, et al. First Trimester Screening for Early and Late Preeclampsia Based on Maternal Characteristics, Biophysical Parameters, and Angiogenic Factors. Prenatal Diagnosis (2015) 35:183-91. doi: 10.1002/pd.4519

33. Crovetto F, Figueras F, Crispi F, Triunfo S, Pugia M, Lasalvia L, et al. Forms of Circulating Luteinizing Hormone Human Chorionic Gonadotropin Receptor for the Prediction of Early and Late Preeclampsia in the First Trimester of Pregnancy. Fetal Diagnosis Ther (2015) 38:94-102. doi: $10.1159 / 000371516$

34. Kuc S, Koster MP, Franx A, Schielen PC, Visser GH. Maternal Characteristics, Mean Arterial Pressure and Serum Markers in Early Prediction of Preeclampsia. PloS One (2013) 8:e63546. doi: 10.1371/ journal.pone. 0063546

35. Lai J, Pinas A, Poon LC, Agathokleous M, Nicolaides KH. Maternal Serum Placental Growth Factor, Pregnancy-Associated Plasma Protein-a and Free $\beta$-Human Chorionic Gonadotrophin at 30-33 Weeks in the Prediction of Pre-Eclampsia. Fetal Diagnosis Ther (2013) 33:164-72. doi: 10.1159/ 000345090

36. Luckas M, Hawe J, Meekins J, Neilson J, Walkinshaw S. Second Trimester Serum Free Beta Human Chorionic Gonadotrophin Levels as a Predictor of Pre-Eclampsia. Acta Obstetricia Gynecologica Scand (1998) 77:381-4. doi: 10.1080/j.1600-0412.1998.770404.x

37. Ozdamar O, Gun I, Keskin U, Kocak N, Mungen E. The Role of Maternal serumbeta-HCG and PAPP-A Levels at Gestational Weeks 10 to 14 in the Prediction of Pre-Eclampsia. Pakistan J Med Sci (2014) 30:568-73. doi: $10.12669 /$ pjms.303.4554

38. Räty R, Koskinen P, Alanen A, Irjala K, Matinlauri I, Ekblad U. Prediction of Pre-Eclampsia With Maternal Mid-Trimester Total Renin, Inhibin A, AFP and Free beta-hCG Levels. Prenatal Diagn (1999) 19:122-7. doi: 10.1002/(sici) 1097-0223(199902)19:2<122::aid-pd491>3.0.co;2-r

39. Suri S, Muttukrishna S, Jauniaux E. 2D-Ultrasound and Endocrinologic Evaluation of Placentation in Early Pregnancy and its Relationship to Fetal Birthweight in Normal Pregnancies and Pre-Eclampsia. Placenta (2013) 34:745-50. doi: 10.1016/j.placenta.2013.05.003

40. Spencer K, Yu CK, Cowans NJ, Otigbah C, Nicolaides KH. Prediction of Pregnancy Complications by First-Trimester Maternal Serum PAPP-A and Free beta-hCG and With Second-Trimester Uterine Artery Doppler. Prenatal Diagn (2005) 25:949-53. doi: 10.1002/pd.1251

41. Spencer K, Yu CK, Savvidou M, Papageorghiou AT, Nicolaides KH. Prediction of Pre-Eclampsia by Uterine Artery Doppler Ultrasonography and Maternal Serum Pregnancy-Associated Plasma protein-A, Free Beta-Human Chorionic Gonadotropin, Activin A and Inhibin A at $22+0$ to $24+6$ Weeks' Gestation. Ultrasound Obstetrics Gynecol (2006) 27:658-63. doi: 10.1002/uog.2676

42. Staboulidou I, Galindo A, Maiz N, Karagiannis G, Nicolaides KH. FirstTrimester Uterine Artery Doppler and Serum Pregnancy-Associated Plasma Protein-a in Preeclampsia and Chromosomal Defects. Fetal Diagn Ther (2009) 25:336-9. doi: $10.1159 / 000235880$

43. Teixeira C, Tejera E, Martins H, Pereira AT, Costa-Pereira A, Rebelo I. First Trimester Aneuploidy Screening Program for Preeclampsia Prediction in a Portuguese Obstetric Population. Obstetrics Gynecol Int (2014) 2014:435037. doi: $10.1155 / 2014 / 435037$

44. Tsai MS, Lee FK, Cheng CC, Hwa KY, Cheong ML, She BQ. Association Between Fetal Nuchal Translucency Thickness in First Trimester and Subsequent Gestational Hypertension and Preeclampsia. Prenatal Diagn (2002) 22:747-51. doi: 10.1002/pd.396

45. Wortelboer EJ, Koster MP, Cuckle HS, Stoutenbeek PH, Schielen PC, Visser GH. First-Trimester Placental Protein 13 and Placental Growth Factor: Markers for Identification of Women Destined to Develop EarlyOnset Pre-Eclampsia. BJOG (2010) 117:1384-9. doi: 10.1111/j.1471-0528. 2010.02690.x

46. Guibourdenche J, Handschuh K, Tsatsaris V, Gerbaud P, Leguy MC, Muller F, et al. Hyperglycosylated hCG Is a Marker of Early Human Trophoblast Invasion. J Clin Endocrinol Metab (2010) 95:E240-4. doi: 10.1210/jc.2010-0138

47. Liu DF, Dickerman LH, Redline RW. Pathologic Findings in Pregnancies With Unexplained Increases in Midtrimester Maternal Serum Human Chorionic Gonadotropin Levels. Am J Clin Pathol (1999) 111:209-15. doi: 10.1093/ajcp/111.2.209

48. Mikat B, Zeller A, Scherag A, Drommelschmidt K, Kimmig R, Schmidt M. BhCG and PAPP-A in First Trimester: Predictive Factors for Preeclampsia? Hypertension Pregnancy (2012) 31:261-7. doi: 10.3109/10641955.2011.638956

49. Taché V, Baer RJ, Currier RJ, Li CS, Towner D, Waetjen LE, et al. PopulationBased Biomarker Screening and the Development of Severe Preeclampsia in California. Am J Obstetrics Gynecol (2014) 211:377.e1-8. doi: 10.1016/ j.ajog.2014.03.026

50. Roiz-Hernández J, de J Cabello-Martínez J, Fernández-Mejía M. Human Chorionic Gonadotropin Levels Between 16 and 21 Weeks of Pregnancy and Prediction of Pre-Eclampsia. Int J Gynaecol Obstetrics (2006) 92:101-5. doi: 10.1016/j.ijgo.2005.10.002

51. Said ME, Campbell DM, Azzam ME, MacGillivray I. Beta-Human Chorionic Gonadotrophin Levels Before and After the Development of Pre-Eclampsia. Br J Obstetrics Gynaecol (1984) 91:772-5. doi: 10.1111/j.1471-0528.1984.tb04848.x

52. Bartha JL, Romero-Carmona R, Escobar-Llompart M, Paloma-Castro O, Comino-Delgado R. Human Chorionic Gonadotropin and Vascular Endothelial Growth Factor in Normal and Complicated Pregnancies. Obstetrics Gynecol (2003) 102:995-9. doi: 10.1016/s0029-7844(03)00808-1

53. Kalinderis M, Papanikolaou A, Kalinderi K, Ioannidou E, Giannoulis C, Karagiannis V, et al. Elevated Serum Levels of interleukin-6, Interleukin- $1 \beta$ and Human Chorionic Gonadotropin in Pre-Eclampsia. Am J Reprod Immunol (NY) (2011) 66:468-75. doi: 10.1111/j.1600-0897.2011.01019.x

54. Gurbuz A, Karateke A, Mengulluoglu M, Gedikbasi A, Ozturkmen M, Kabaca C, et al. Can Serum HCG Values be Used in the Differential Diagnosis of Pregnancy Complicated by Hypertension? Hypertens Pregnancy (2004) 23:112. doi: $10.1081 /$ prg-120028276

55. Dugoff L, Hobbins JC, Malone FD, Porter TF, Luthy D, Comstock CH, et al. First-Trimester Maternal Serum PAPP-A and Free-Beta Subunit Human Chorionic Gonadotropin Concentrations and Nuchal Translucency Are 
Associated With Obstetric Complications: A Population-Based Screening Study (The FASTER Trial). Am J Obstetrics Gynecol (2004) 191:1446-51. doi: 10.1016/j.ajog.2004.06.052

56. Yu H, Shen YT, Li HL, Yan Y, Ren ML, Wang B. The Relationship Between Maternal Serum Prenatal Screening Combined With Epidemiological Study and Early Onset Preeclampsia. Arch Gynecol Obstetrics (2014) 289:749-53. doi: 10.1007/s00404-013-3039-x

57. Burton GJ, Redman CW, Roberts JM, Moffett A. Pre-Eclampsia: Pathophysiology and Clinical Implications. BMJ (Clinical Res ed.) (2019) 366:12381. doi: 10.1136/bmj.12381
Conflict of Interest: The authors declare that the research was conducted in the absence of any commercial or financial relationships that could be construed as a potential conflict of interest.

Copyright (C) 2021 Zhang, Huangfu, Shi and Xiao. This is an open-access article distributed under the terms of the Creative Commons Attribution License (CC BY). The use, distribution or reproduction in other forums is permitted, provided the original author(s) and the copyright owner(s) are credited and that the original publication in this journal is cited, in accordance with accepted academic practice. No use, distribution or reproduction is permitted which does not comply with these terms. 